\title{
The Excavation of Iron Age Working Floors and Small-Scale Industry at Ban Non Wat, Thailand
}

\author{
Belinda J. Duke \\ James Cook University, Townsville, Australia
}

\author{
Alison K. Carter \\ University of Wisconsin-Madison, USA
}

\author{
Nigel J. Chang \\ James Cook University, Townsville, Australia
}

\section{Introduction}

The prehistoric moat-mound site of Ban Non Wat (BNW) is located on the Khorat Plateau in Northeast Thailand (figure 1). Initially identified due to its Iron Age moats, BNW has provided a wealth of information about changing social complexity, based largely on the extensive number of graves recovered over the first seven seasons of excavation (Higham 2009). Occupation layers dating from the Neolithic (c. 1750 BC) through to the Iron Age (AD 500) allow for a deep view into the prehistory of Northeast Thailand (Higham and Higham 2009). This report details the discovery of Iron Age clay-lined working floors found in excavation squares V200 and W200 during the 20082009 and 2009-2010 field seasons, as part of the new and ongoing project at the site codirected by Drs. Nigel Chang, Kate Domett, Amphan Kijngam, Warrachai Wiriyaromp and Prof. Bill Boyd. In this report we examine one hypothesis that argues these floors may be associated with small-scale metal and salt production at the site. This is an ongoing project and more evidence will be gathered during future fieldwork to further test this hypothesis.

\section{The Excavation}

To date over $1100 \mathrm{~m} 2$ have been opened at BNW, with V200 and W200 contributing to the current aim of sampling across the whole of the site (figure 2). These units were chosen due to their location mid-way down the eastern slope of the mound. Excavation in this area began with a single four by four metre unit that was progressively extended, initially in order to investigate an Iron Age water management device (channel) that Duke (2009) argues was designed to divert water away from the mound and acted as a physical boundary within the site. While the relationship between this feature and the working floors is unclear, its presence emphasises that the Iron Age was a period of intense activity in this particular area. 


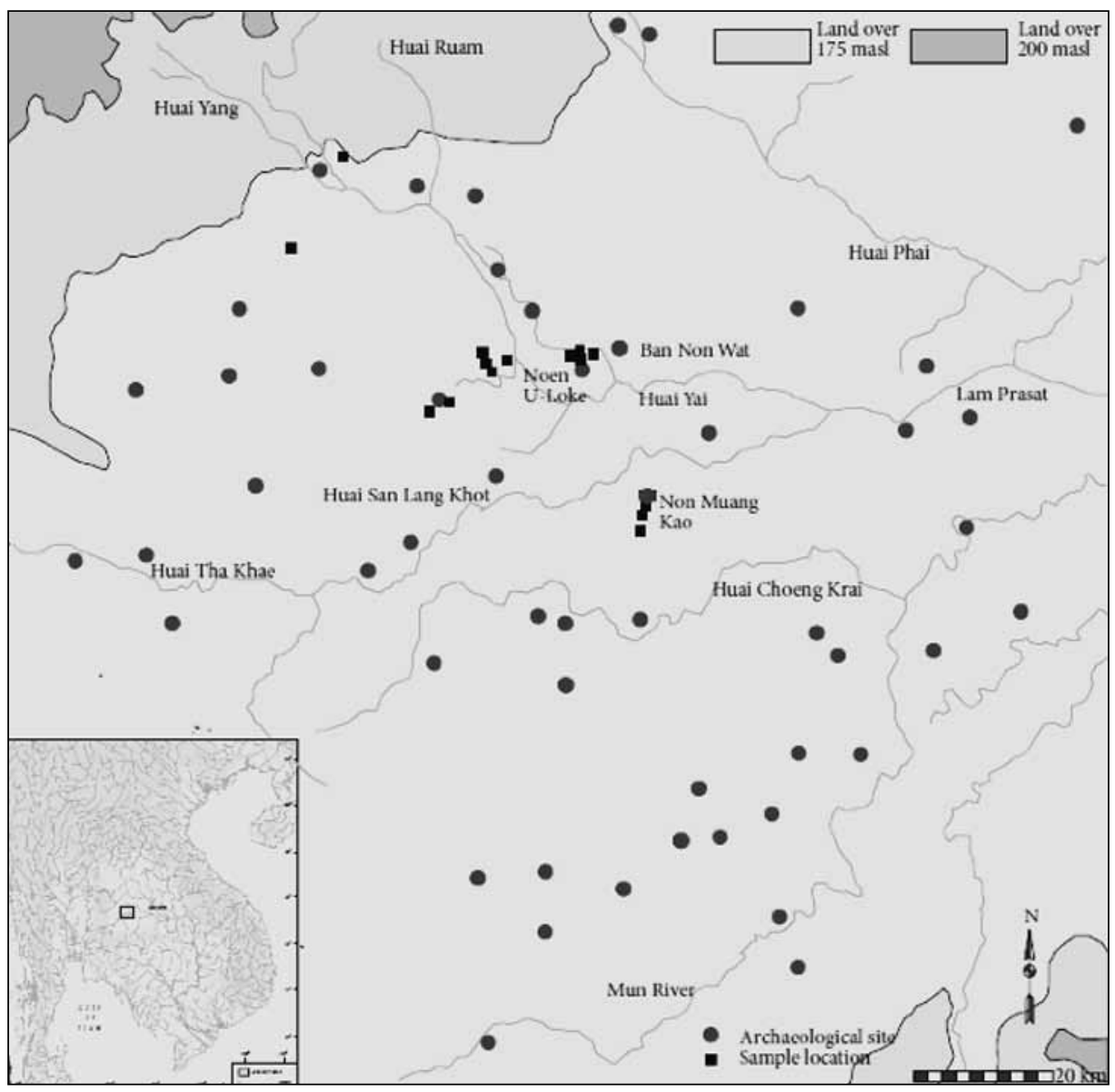

Figure 1. Map of Region (from Boyd and Habberfield-Short 2007).

\section{Results}

Seven cultural layers were documented in excavation units V200 and W200. Up to a dozen floors/surfaces were identified specifically in layers four and five, between 1.7 and $2.2 \mathrm{~m}$ below ground surface. These hard floors were primarily baked clay or compacted surfaces, which varied in colour and texture ranging from yellows, greys, and reds to blackened concreted floors inlayed with burnt coarse material. Some were clearly demarcated across the unit, while others merged into earlier floors suggesting they were disturbed by continuous activity. Figure 3 shows in plan form the first set of floors encountered and demonstrates the complex layering of contexts found throughout the excavation. Figure 4 shows additional hard floor surfaces overlapping and intercutting one another. 


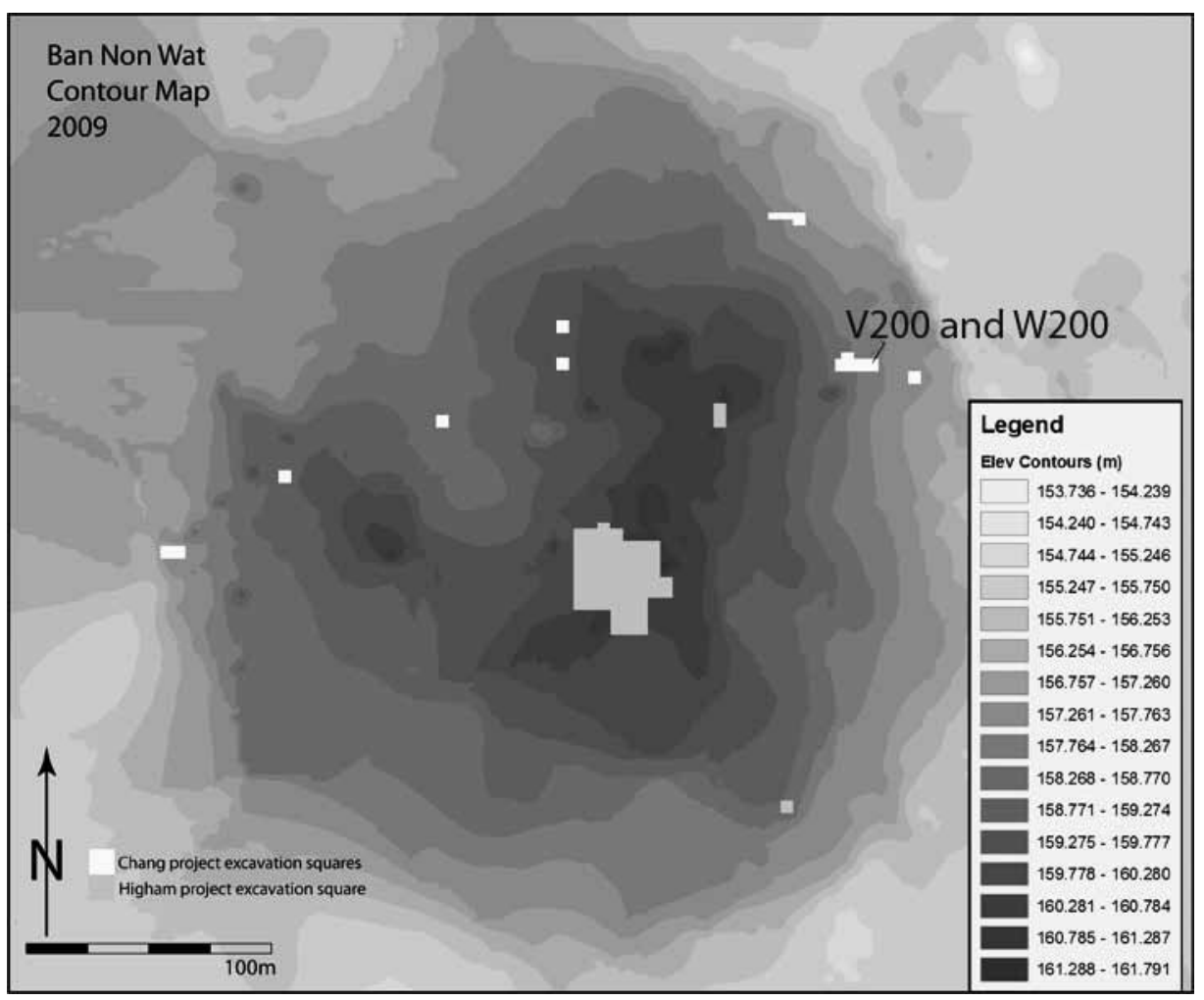

Figure 2. Contour Elevation map of Ban Non Wat showing square location.

In addition to the floors themselves, there were also a series of associated features including feature 22 (context number 16581) identified as a pyro-technological feature. This feature consists of baked red clay that covered a baked clay base associated with several fragmented crucibles, as well as bronze and iron fragments (figure 5). The crucibles were relatively well preserved with one about $80 \%$ complete. Much of the inner surface of the crucibles was stained green, which may indicate the presence of copper. Vitrified sections indicate that they were exposed to intense heat. The associated baked clay consists of two oval-shaped baked clay sections, which were separated by a narrow space. Together, these finds suggest a metal working furnace where the 'narrow space' may have accommodated an inlet for an oxygen supply needed to achieve the high temperatures required for smithing. Recent research on metallurgy at BNW indicates that smithing was a more common activity than smelting (see Cawte and Boyd 2010).

Clay floors have been found at sites across Northeast Thailand and particularly close to BNW. For example, they have been found at the site of Non Muang Kao (NMK) located within kilometres of BNW (O'Reilly 1997). The NMK floors primarily consisted of thin white clay deposits and are believed to be associated with domestic use or possibly related to burials and mortuary practice (O'Reilly 1997). In contrast, we believe the clay 


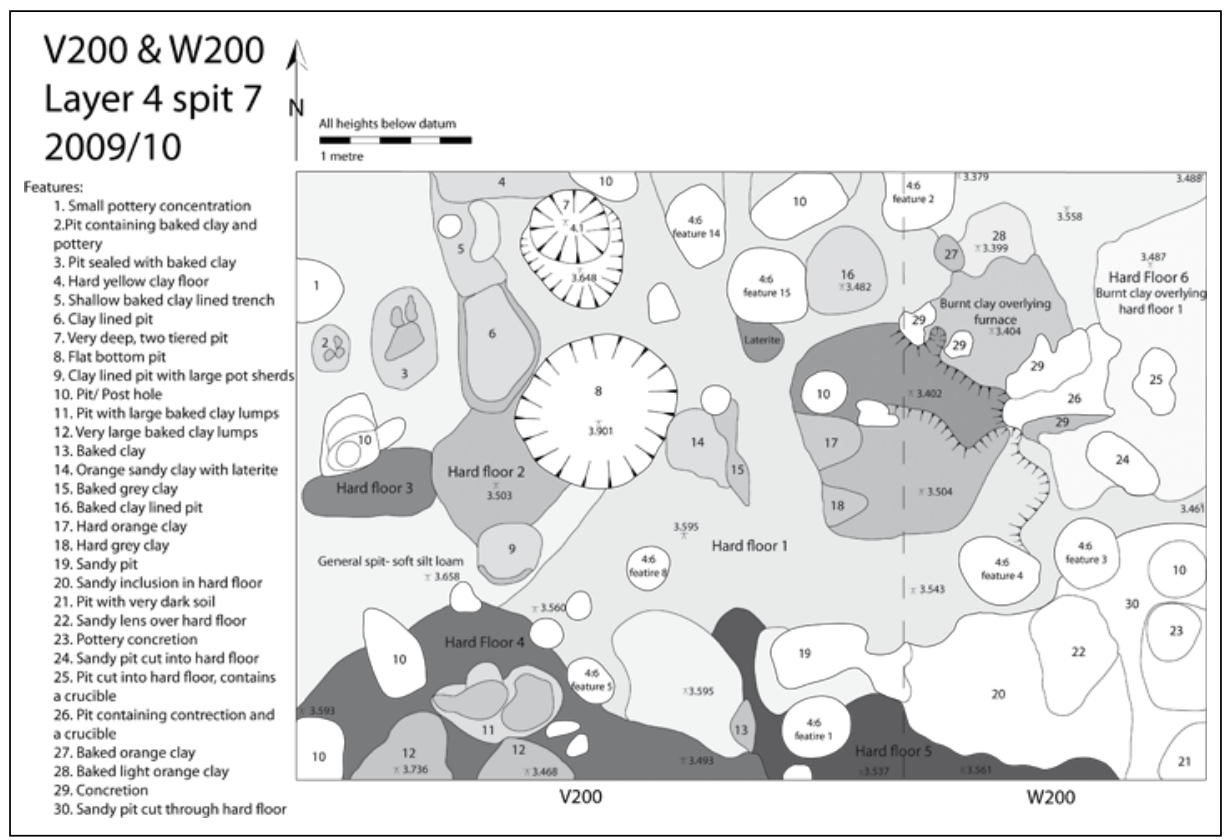

Figure 3. Plan view of V200 and W200, Layer four Spit seven (map B. Duke).

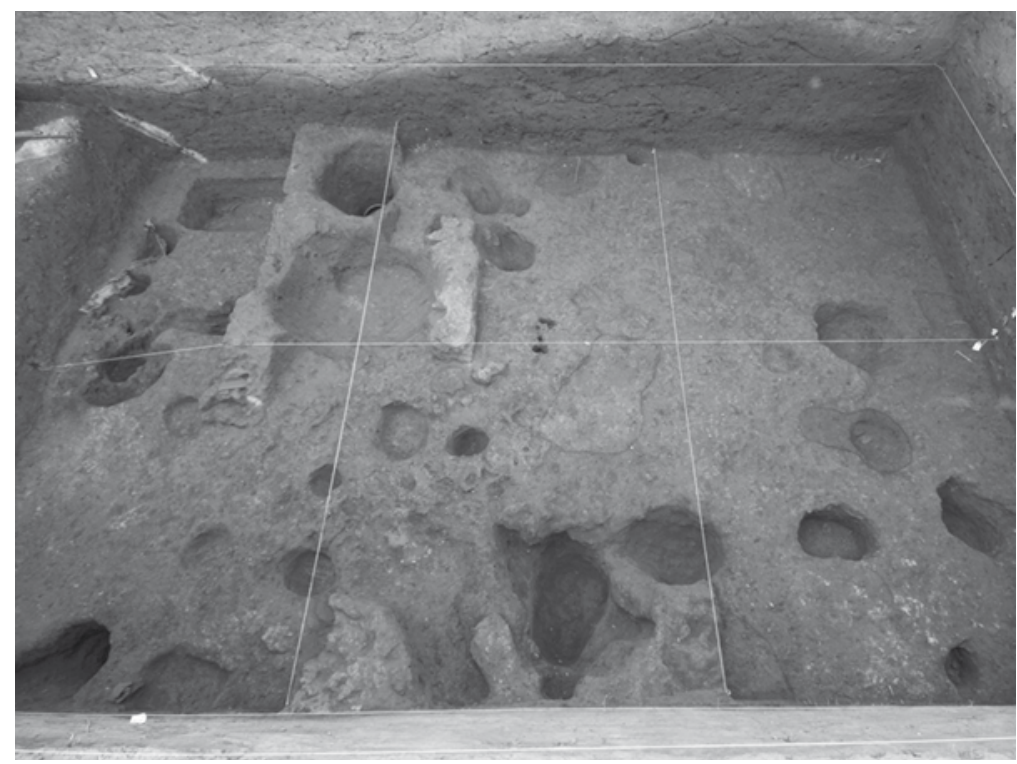

Figure 4. Hard floor surfaces in squares V200 and W200 (Photo N. Chang). 
floors at BNW are related to, or are by-products of, pyro-technological activities, most likely metal production. The possible furnace, crucible fragments and metal fragments found associated with the hard floors all point toward small-scale metal production. Furthermore, 'a remarkable series of artefacts employed in metallurgy' have been found in Iron Age contexts in other parts of the site (see Higham 2009: 293).

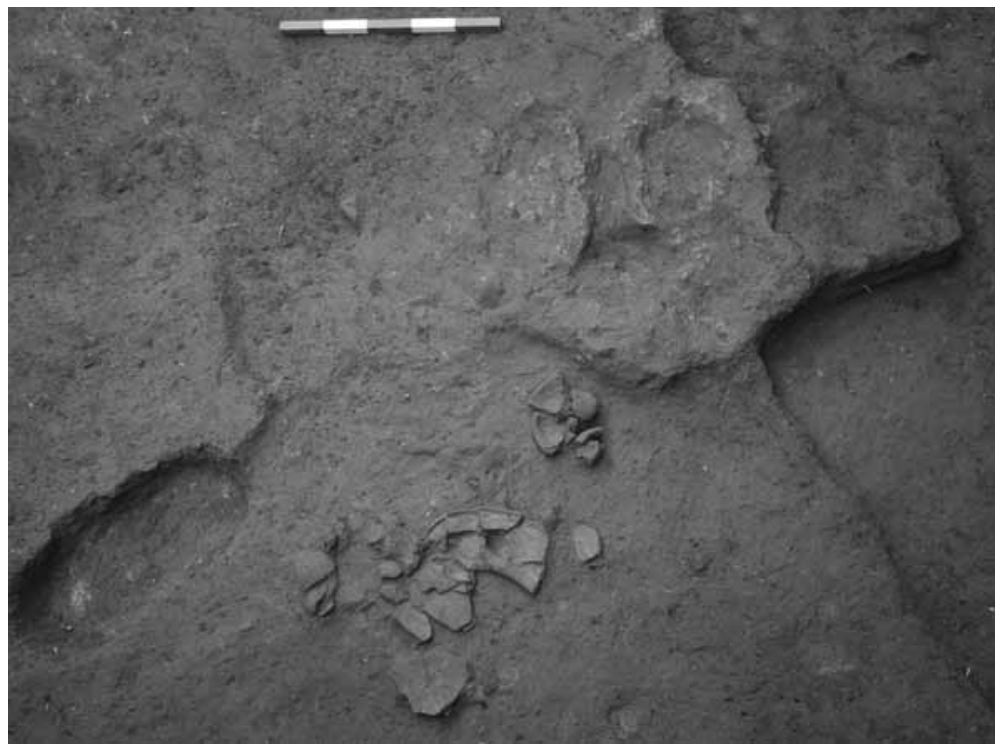

Figure 5. Feature 22, a baked clay object, in the upper right hand corner with associated crucible fragments (Photo N. Chang).

Additional features were also encountered, including many pits and holes that were cut into the floors. These pits ranged in size from diameters of 20 to $40 \mathrm{~cm}$ and depths of 15 to $45 \mathrm{~cm}$. Three contained large irregular blocks of baked clay that appear to have been fired in place. Four of the pits appear to have been lined with $1 \mathrm{~cm}$ or more of baked clay. Many of the pits were partially filled with either fine or coarse red sand. The largest of these pits are features seven and eight (figure 3 and figure 6). Feature seven was almost $1 \mathrm{~m}$ deep and $50 \mathrm{~cm}$ in diameter. It was dug down to the natural yellow clay in two phases, with the lower section filled with fine red sand and the upper section containing a sherdy/shell mix. Feature eight was a flat-bottom pit, approximately $50 \mathrm{~cm}$ deep, $1 \mathrm{~m}$ in diameter and lined with a thin layer of clay. In addition to their large size, these pits differ in that they do not appear to have been heat-treated or fired. We argue that these pits were used in salt production.

Evidence for salt production has been identified at many sites in Northeast Thailand, including Non Tung Pie Pone (NTPP) where its production seems to be on a large scale (Nitta 1997). Figure 6 shows an example of prehistoric remains (features seven and eight in figure 3) compared with modern salt making practices. The parallels are 
significant, with modern techniques closely mimicking those used in prehistory. The Khorat Plateau, the region in which both BNW and NTPP lie, is rich in natural saline deposits that are still utilised by modern local large-scale industries today. The local 'household' level production of salt is still widely practiced in the region and can be observed when visiting the region through the late dry season. It should be noted that the shape of the saline water storage pit used at BNW differs from those found at NTTP, which are rectangular. This difference may be attributed to the variety of techniques used by the individual salt makers and the quantity of salt that was made. Both modern circular and rectangular storage techniques can be observed today within five kilometres of BNW (see Cawte and Bongsasilp 2009; Yankowski 2009).

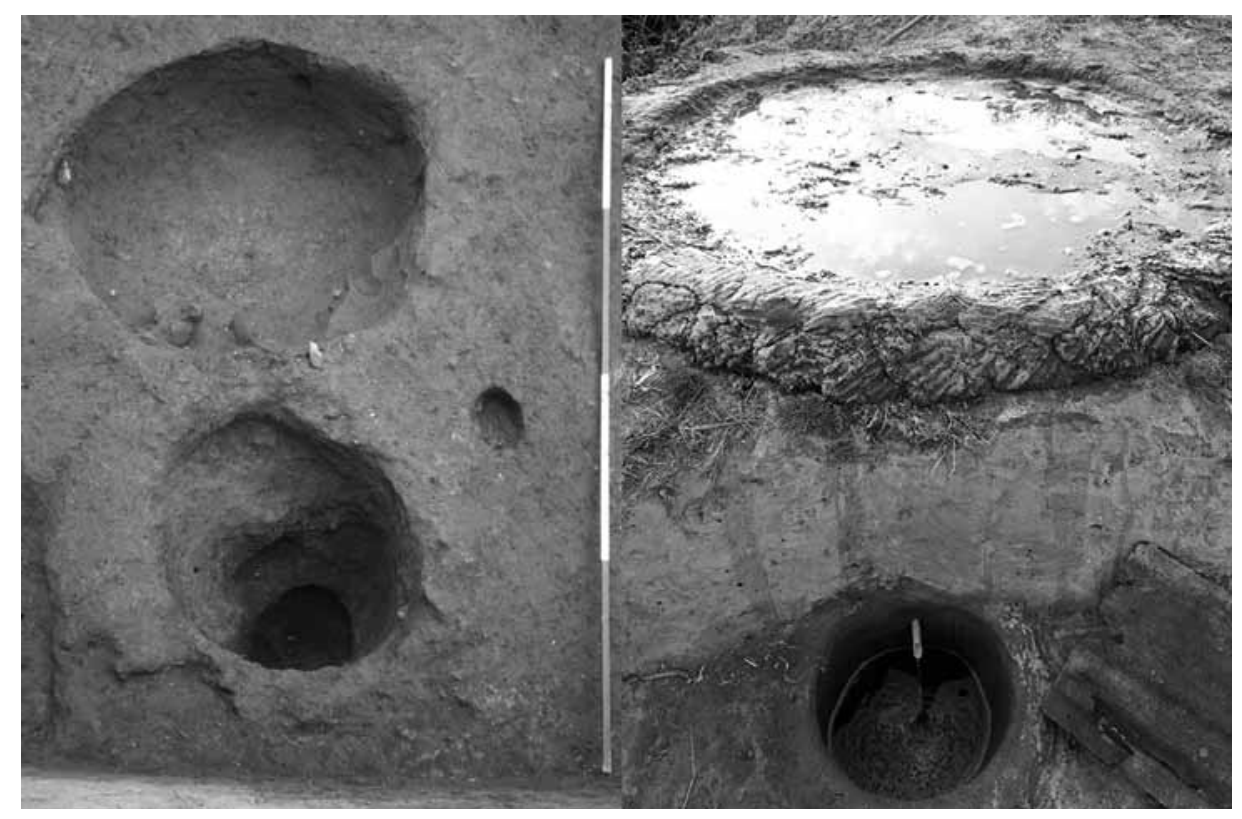

Figure 6. Comparison of pre-historic (left) and modern (right) salt production on the Khorat Plateau (photo N. Chang). On the left: Feature seven is the deep hole closest to the bottom of the frame, feature eight is the shallower, wider hole above.

\section{Interpretation and Conclusion}

While evidence for metal and salt production seems to be present at the site, it is not on the same large scale documented at other Iron Age sites in Northeast Thailand. For example, at the site of Ban Don Phlong iron-smelting was happening on a much larger scale, as groups of furnaces were found together and showed repeated reconstruction and reuse over several periods (Nitta 1997). Excavations at NTTP uncovered nine phases of intensive salt production activities. In fact it is argued that 'the mound itself was almost entirely constructed by the dumped soil from the salt-making activities,' (Nitta 1997: 158). 
The small-scale of these activities at BNW, as well as their presence within a restricted area, suggests that this location may have been used by a family unit or kin group. A family or household unit may switch between industries dependent on varying external factors, such as the season or the availability of resources. Thus, in this paper we argue that the patterns of features we see at BNW may result from a seasonal rotation between activities within family units, generating the resources they needed to live comfortably during the Iron Age. If these preliminary conclusions are supported by further research then the presence of both large-scale and small-scale metal and salt production across the region would indicate diversity in how Iron Age communities organized their production activities in Northeast Thailand. This research also emphasizes the value of non-mortuary data for understanding the nature of social complexity and organization during the Iron Age and highlights the importance of sampling at numerous locations across a site in order to better capture the life ways of ancient peoples. We look forward to continued excavation and research at Ban Non Wat.

\section{Acknowledgements}

The authors wish to thank the Earthwatch Institute and the many Earthwatch volunteers who have supported and worked at Ban Non Wat. We are grateful to the Fine Arts Department of Thailand and the National Research Council of Thailand for allowing us to continue excavation and research at BNW. We also wish to acknowledge the project co-directors Kate Domett, Amphan Kijngam, Warrachai Wiriyaromp and Prof. Bill Boyd. Jodie Mitchell and Jo Shoebridge also supervised the excavation of squares V200 and W200. Oliver Pryce and Hayden Cawte provided valuable insight on metal production. Lastly we are most indebted to the people of Ban Non Wat who have welcomed us into their village.

\section{References}

Boyd, W. E. and Habberfield-Short, J. 2007. Geoarchaeological landscape model of the Iron Age settlements of the Upper Mun River floodplain. In Higham, C. F. W. and Thosarat, R. (eds.) The Origins of the Civilization of Angkor: The Excavation of Noen U-Loke and Non Muang Kao. Bangkok: Thai Fine Arts Department, 1-28.

Cawte, $\mathrm{H}$ and Bongsasilp, B. 2009. 'An Ethnoarchaeological Investigation of Household Salt Making in Northeast Thailand: a Scalar Hypothesis for Prehistoric Production.' Paper read at the 19th Indo-Pacific Prehistory Association Congress Conference, 29th November- 5th December. Hanoi, Vietnam.

Cawte, H and Boyd, W. 2010. Laterite Nodules: a Credible Source of Iron Ore in Iron Age Northeast Thailand? Geoarchaeology 25(5), 626-644, doi:10.1002/gea.20326.

Duke, B. J. 2009. This is Not a Moat: Water and Boundaries at Ban Non Wat, Northeast Thailand. Unpublished honours dissertation. Townsville: James Cook University.

Higham, C. 2009. The Origins of Angkor, Volume 3: The Excavation of Ban Non Wat, Introduction. Bangkok: Thai Fine Arts Department.

Higham, C. and Higham, T. 2009. A New Chronological Framework for Prehistoric Southeast Asia Based on a Bayesian Model From Ban Non Wat. Antiquity 83, 125-144. 
Nitta, E. 1997. Iron-smelting and Salt-making industries in Northeast Thailand. IndoPacific Prehistory Association Bulletin 16(3), 153-160.

O'Reilly, D. J. W. 1997. The Discovery of ClayLined Floors at an Iron Age Site in Thailand; Preliminary Observations from Non Muang Kao, Nakon Ratchasima Province. Journal of the Siam Society 85 (1), 1-14.
Yankowski, A. 2009. 'Salt production in the Mum River Valley past and present.' Paper read at the 19th Indo-Pacific Prehistory Association Congress Conference, 29th November- 5th December 2009. Hanoi, Vietnam. 